\title{
ESTUDO E AVALIAÇÃO DE MÉTODOS DE SÍNTESE E CARACTERIZAÇÃO DE GRAFENO
}

\author{
A. P. OLIVEIRA ${ }^{1}$, H. Y. KITAMURA ${ }^{1}$ e V. S. AGUIAR ${ }^{1,2}$ \\ ${ }^{1}$ Faculdade de Engenharia de Sorocaba, FACENS \\ 2 Universidade Estadual de Campinas, UNICAMP \\ E-mail para contato: amanda.prietoo@gmail.com
}

\begin{abstract}
RESUMO - O material em estudo, o grafeno, em sua forma cristalizada, possui excelentes propriedades ópticas, térmicas e elétricas que são significativas e úteis em diversas aplicações, desde que sua síntese ocorra de forma controlada, com um adequado teor de pureza. Com o objetivo de explorar e investigar as possibilidades em desenvolvimento relativas à síntese deste material, o presente trabalho promoveu um estudo sobre alguns métodos de síntese e caracterização do grafeno, um nanomaterial da família de alótropos do carbono. Tais métodos foram descritos com o objetivo de se analisar e avaliar aqueles que proporcionaram maior eficiência de síntese. Como resultado da pesquisa realizada, pode-se afirmar que as rotas de processos de síntese do tipo top-down forneceram os melhores resultados, devido à geração de grafeno de alta qualidade, com alto rendimento e baixo custo, garantindo a possibilidade de seu uso industrial aplicado na elaboração de outros materiais como, por exemplo, na composição de películas, fundamentais para a proteção de equipamentos que dependem de energia térmica e elétrica para seu funcionamento.
\end{abstract}

\section{INTRODUÇÃO}

$\mathrm{O}$ estudo dos nanomateriais pertence à área da nanotecnologia, que compreende o desenvolvimento e a construção de circuitos elétricos, com extensões ou tamanho equiparados aos átomos e as moléculas. É fundamental a fabricação dos mesmos, pois eles representam materiais com funcionalidades variáveis e, geralmente, apresentam maior desempenho que aqueles usualmente fabricados em maior escala. As nanoestruturas de carbono vêm se destacando devido a suas diferentes formas estruturais e propriedades especiais.

O grafeno, alótropo do carbono, é um dos mais promissores nanomateriais em estudo. Sua estrutura é composta por átomos de carbono com hibridização $\mathrm{sp}^{2}$, ligados e dispostos em um retículo bidimensional.

O grande desafio tecnológico é o isolamento de grafeno em quantidades razoáveis e a baixo custo para aplicações industriais (FIM, 2012). Uma maneira de baixo custo é obter o grafeno a partir da grafite. Em 2004, pesquisadores conseguiram isolar pequenos fragmentos esfoliados a partir da grafite e, após sua caracterização, verificaram que se tratava de uma estrutura com uma única camada de átomos de carbono (PEI et al., 2010). 
A estrutura da grafite é a combinação de folhas de grafeno deslocados alternadamente. Outros alótropos do carbono, como os fulerenos e os nanotubos de carbono são folhas de grafeno enroladas, formando uma esfera e um cilindro, respectivamente, conforme mostra a Figura 1.

Figura 1 - Construção de três alótropos de carbono a partir da monocamada de grafeno.

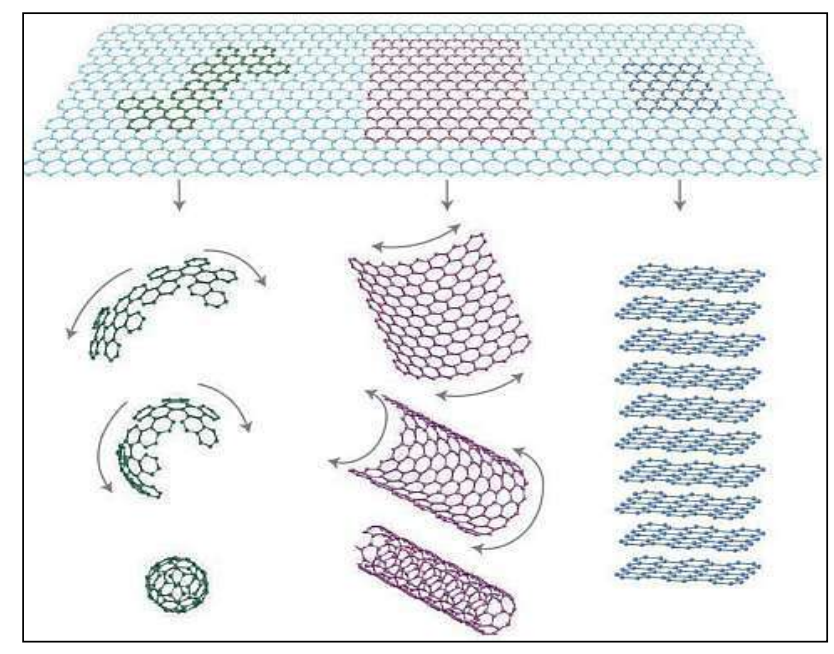

No mundo da ciência, investigações estão sendo feitas para obtenção do grafeno de maneira simples e com baixo custo. Atualmente, duas rotas de processos têm sido trabalhadas: 1) rota bottom-up, que está relacionada com a síntese do material, e 2) rota topdown, que consiste na fragmentação do material até alcançar a escala desejada (FIM, 2012).

Um aspecto negativo na obtenção do material é que suas propriedades ideais estão disponíveis somente quando isolado, ou seja, se o grafeno sintetizado permanecer agregado a outro material, essas propriedades são reduzidas. Com isso, este trabalho tem o propósito de apresentar alguns estudos envolvendo os processos top-down para a obtenção do grafeno, de maneira que sua síntese e caracterização serão descritos ao longo do texto.

\section{NATUREZA E ASPECTOS DOS COMPONENTES}

\subsection{Grafite}

A grafite é uma modificação do carbono, de aparência cinza metálico. Este material consiste em um mineral na forma de flocos ou em pó com vários tamanhos de partículas. Sua forma consiste em cristais hexagonais ligados por ligações covalentes, com empilhamento de camadas planares na estrutura, conforme mostra a Figura 2.

Figura 2 - Representação da estrutura da grafite. 


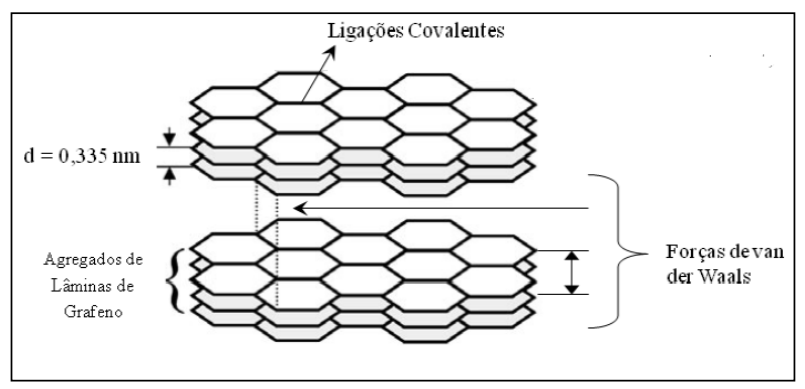

Cada camada que compõe a grafite é formada por planos laminares de grafeno. Entre essas camadas estão presentes as forças de ligação de van der Waals do tipo dipolo induzidodipolo induzido. A distância entre as camadas é da ordem de 0,335 nm.

A estrutura específica da grafite possibilita ao material uma ótima condutividade elétrica, da mesma ordem de grandeza dos condutores metálicos $\left(10^{4} \mathrm{~S} \mathrm{~cm}^{-1}\right)$, no sentido paralelo aos planos e uma condutividade $10^{5}$ vezes menor no sentido perpendicular aos planos (FIM, 2012), além de uma notável maciez e ação lubrificante devido as fracas ligações entre as camadas do grafeno, que possibilita o deslizamento das mesmas, umas sobre as outras.

Devido às características benéficas do material grafeno, o interesse das empresas em trabalhar com a grafite tem aumentado, no sentido de investigar e explorar formas diferentes de síntese do nanomaterial.

\subsection{Grafeno}

Grafeno é o nome dado a um hidrocarboneto policíclico aromático, com anéis de seis carbonos exclusivamente, que se estendem alternada e infinitamente em um plano bidimensional (NUNES, 2013). Esse nanomaterial se apresenta sendo o bloco básico de construção para a família de cristais alótropos do carbono, com exceção do diamante.

Suas propriedades são excelentes, tais como boa condutividade elétrica, similar ao metal cobre, resistência física superior ao diamante e é um excelente condutor de calor, superando os demais materiais condutores.

No começo dos estudos do grafeno, os físicos Rudolf Peierls, Lev Landau e Evgene Lifshitz afirmavam que o grafeno não existia experimentalmente. Essa teoria apontava que flutuações térmicas existentes em temperaturas finitas conduziriam redes cristalinas de baixa dimensão ao colapso, por induzir deslocamentos atômicos comparáveis às distâncias interatômicas (CASTRO, 2011). Portanto, obter o grafeno exigiria mais do que um método normal.

Mais tarde, pesquisas focadas no estudo do grafeno realizadas pelos professores Andre Geim e Konstantin Novoselov da Universidade de Manchester, permitiram que estes ganhassem o Prêmio Nobel de Física em 2010, já que chegaram a obter o grafeno de modo simples. Em seu experimento usaram uma fita adesiva e a colaram repetidas vezes no grafite. Esse movimento esfoliava o grafite, e na fita monocamadas do grafeno ficavam retidas. $\mathrm{O}$ acontecimento foi um marco histórico, ampliando a visão de estudiosos e expandindo os estudos de diferentes sínteses do grafeno (CASTRO,2011). 


\section{PRINCIPAIS MÉTODOS DE OBTENÇÃO DE GRAFENO}

Nos processos bottom-up, o grafeno pode ser sintetizado através de métodos como 1) crescimento epitaxial em substrato isolante, 2) deposição química de vapor pelo método de CVD, 3) redução de $\mathrm{CO}$ e 4) descarga de arco. Esses métodos garantem uma lâmina de grafeno em alto grau de pureza e isenta de defeitos, mas há a desvantagem da produção acontecer em pequena escala.

Nos processos top-down, o grafeno pode ser sintetizado por separação e /ou esfoliação da grafite. Os principais métodos são 1) esfoliação química e 2) esfoliação mecânica. Esses métodos oferecem a vantagem de partir de um material de baixo custo econômico como a grafite. Além disso, é iminente produzir em larga escala, o que é relevante para a aplicação, por exemplo, em placas de energia solar.

A rota top-down indica a obtenção do grafeno ou grafeno modificado através da grafite ou óxido de grafite, conforme mostra a Figura 3.

Figura 3 - Métodos top-down para a produção de grafeno ou grafeno modificado.

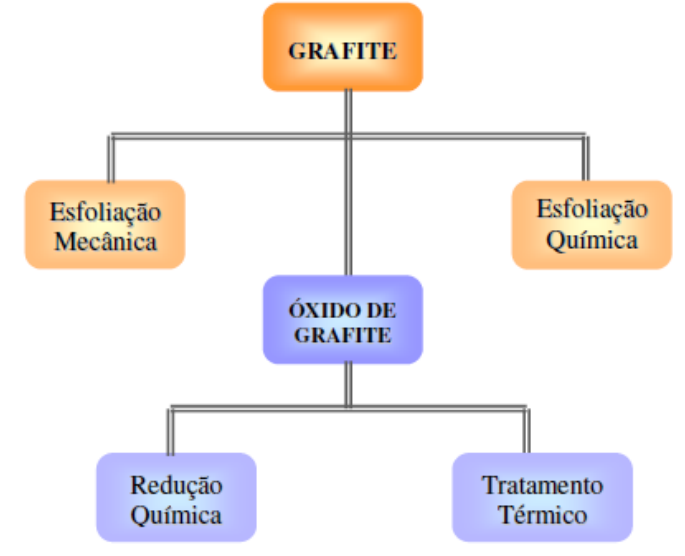

O método de esfoliação mecânica está relacionado com a descamação das monocamadas de grafeno do floco de grafite com o auxílio de uma fita adesiva. De partida, o primeiro passo é usar a fita em uma série de repetições de movimento de "colagem e descolagem". O segundo passo é banhar a fita em uma solução com acetona junto a um substrato de Si dopada com uma camada de sílica. As lâminas de grafeno ficam retidas na superfície da sílica $\left(\mathrm{SiO}_{2}\right)(\mathrm{FIM}, 2012)$.

O método de esfoliação química é fundamentado na modificação da estrutura da grafite por tratamentos físicos e químicos. Para facilitar a esfoliação é usado um tipo de grafite chamada Composto de Grafite Intercalado (GIC), que possui átomos ou moléculas intercaladas entre as camadas do grafeno, chamadas agentes intercalantes. A preparação do grafite GIC é por meio da reação que ocorre entre a grafite e um oxidante forte (por exemplo, ácido sulfúrico concentrado), demonstrada na Equação 1 . O número $n$ designa o número de lâminas de grafeno que separam as camadas intercaladas adjacentes.

$$
n(\text { grafite })+n \mathrm{H}_{2} \mathrm{SO}_{4}+\frac{n}{2}[\text { oxidante }] \rightarrow n\left[\text { grafite }-\mathrm{HSO}_{4}\right]+\frac{n}{2} \mathrm{H}_{2} \mathrm{O}
$$


As ligações dos cristais hexagonais são fortes devido à hibridização $\mathrm{sp}^{2}$ que permite a formação de três ligações sigma. Já nas lâminas empilhadas, atua uma ligação secundária (intensidade inferior a ligação primária covalente sigma) de forças de dispersão de London (dipolo induzido-dipolo induzido), que proporciona um espaço entre camadas disponível de ocupação pelos agentes ligantes, ampliando o espaçamento interplanar dos cristais da grafite sem interromper ou desfazer as camadas de carbono.

O grafite GIC é submetido ao tratamento de oxidação. O grafeno passa a ser óxido de grafeno ou grafeno modificado, onde as lâminas são fortemente hidrofílicas, devido à intercalação de moléculas de água entre elas.

A próxima etapa é esfoliar o óxido de grafite. Forças irão atuar nas lâminas para ocorrer uma separação. Duas maneiras são apresentadas, pelos métodos mecânicos (ultrassom e /ou agitação mecânica) ou por tratamento térmico em temperaturas elevadas.

Após a esfoliação, obtêm-se as lâminas de grafeno quimicamente modificadas, que os torna um nanomaterial eletricamente isolante devido à oxidação, direcionando para uma mudança da hibridização do carbono de $\mathrm{sp}^{2}$ para $\mathrm{sp}^{3}$. Para voltar às propriedades iniciais do grafeno, o óxido de grafeno será reduzido pela rota de redução química ou térmica.

A redução química baseia-se em uma dispersão coloidal estável, seguida de redução, por uma variedade de meios químicos (FIM, 2012). A preocupação nessa rota é a presença de impurezas, que podem estar presentes dependendo do solvente escolhido para dispersar sua lâmina de óxido de grafeno.

A redução térmica baseia-se no rápido aquecimento do óxido sob um gás inerte e em altas temperaturas, permitindo a ocorrência da redução e da esfoliação do óxido, produzindo lâminas de grafeno termicamente reduzidas (FIM, 2012), restaurando os planos da estrutura eletrônica, além de ser uma boa opção para assegurar que o nanomaterial grafeno tenha o mínimo de impureza.

Como exemplo de síntese com resultados experimentais positivos, tem-se a rota topdown, com o método de esfoliação química. Este método permitiu o preparo da grafite GIC obtida por meio do ácido sulfúrico em que, após o processo de oxidação, o material foi esfoliado por métodos mecânicos, e reduzido termicamente (FIM, 2012).

A estrutura do cristal dos flocos de grafite e das nanolâminas de grafeno (NG) foram analisadas por meio da técnica de difração de raios-X, conforme mostra o difratograma da Figura 4.

Figura 4 - Difratograma de raios-X: floco de grafite $\left(2 \theta=26,67^{\circ}\right), \mathrm{NG}\left(2 \theta=26,52^{\circ}\right)$. 

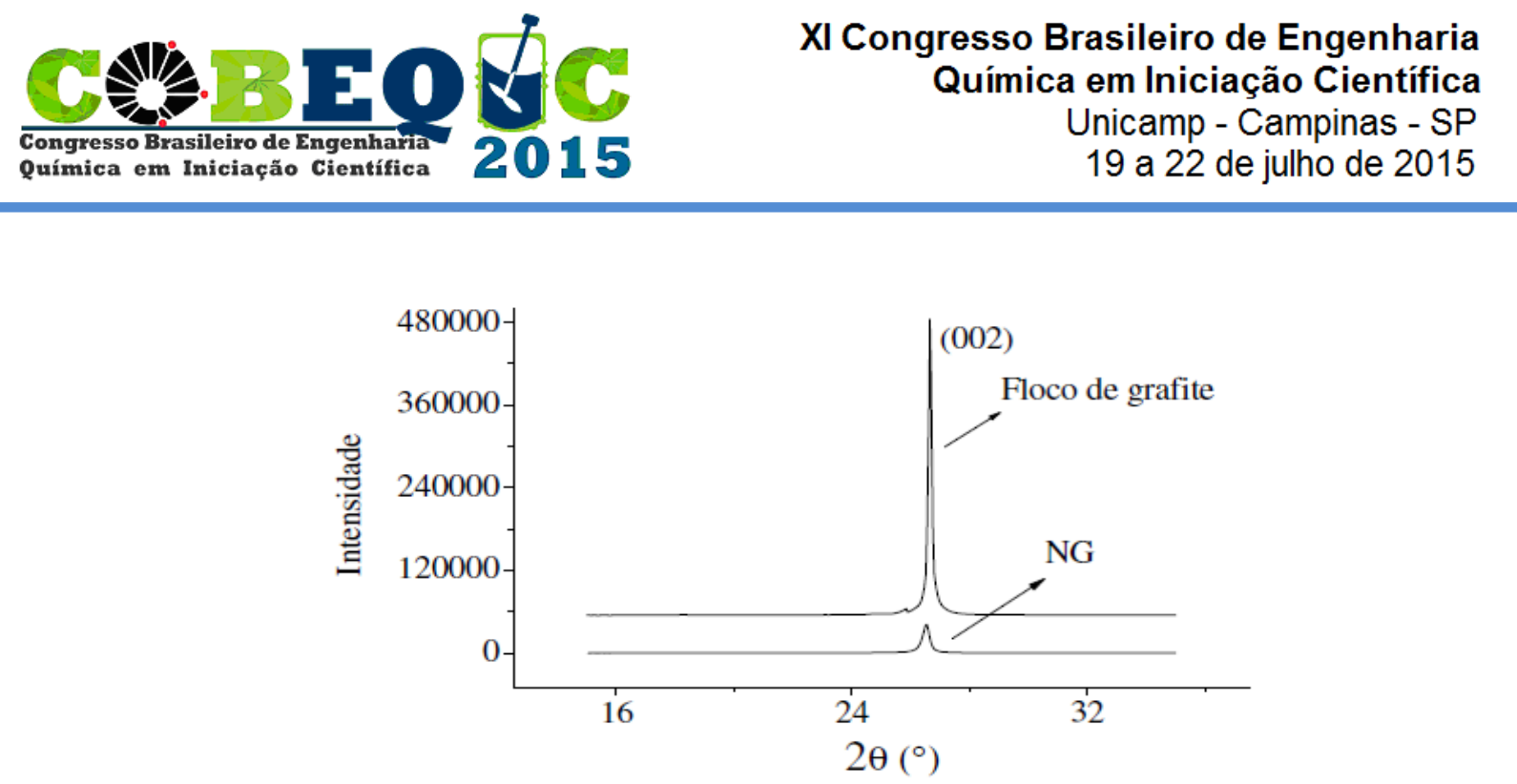

A imagem do difratograma confirma que os tratamentos não destruíram a estrutura lamelar da grafite, devido à proximidade entre os picos, considerando o uso de amostras de massas iguais. Os efeitos de diminuição na intensidade da banda e o alargamento da mesma para o NG indicaram uma menor organização, comparada com o floco de grafite. Este comportamento é resultado de defeitos nos cristais.

\section{CONSIDERAÇÕES FINAIS}

O grafeno é um nanomaterial promissor para o futuro da tecnologia, por possuir propriedades exclusivas e excepcionais. Por meio da pesquisa bibliográfica realizada, pode-se afirmar que o método esfoliação química pela rota top-down apresenta alta eficiência de síntese, pois obtém o material em grandes quantidades e com qualidade, favorecendo aplicações do grafeno na fabricação de outros materiais, além de ser uma rota de baixo custo que beneficia as indústrias. Por fim, pode-se afirmar que este procedimento experimental (esfoliação química) realizado para obter o óxido de grafeno, até o processo redutivo do mesmo, mostrou a possibilidade de síntese do nanomaterial na forma de lâminas.

\section{REFERÊNCIAS BIBLIOGRÁFICAS}

CASTRO, M. O. de. Síntese do grafeno pelo método cvd. 2011. 85 f. Dissertação (Mestrado) - Departamento de Física, Universidade Federal do Ceará, Fortaleza, 2011.

FIM, F. de C. Síntese e propriedades de nanocompósitos de polietileno/nanolâminas de grafeno obtidos através de polimerização in situ. 2012. 105 f. Tese (Doutorado) Instituto de Química, Universidade Federal do Rio Grande do Sul, Porto Alegre, 2012.

NUNES, L. O. Síntese, caracterização e aplicação do óxido de grafite e grafeno em estudos eletroquímicos envolvendo ácido ascórbico, ácido úrico, dopamina e epinefrina. 2013. 104 f. Dissertação (Mestrado) - Faculdade de Ciências Sociais Aplicadas e Exatas, Universidade Federal dos Vales do Jequitinhonha, Diamantina, 2013.

PEI, Q. X.; ZHANG, Y. W.; SHENOY, V. B. A molecular dynamics study of the mechanical properties of hydrogen functionalized graphene. Carbon, v. 48, n. 3, p. 898-904, 2010. 